\title{
As viagens etnográficas e o turismo cultural na obra de Mário de Andrade
}

\author{
The ethnographic trips and the cultural tourism in the work of Mário de Andrade \\ Las viajes etnográficos y el turismo cultural en la obra de Mário de Andrade
}

Janaina Costa Sousa

Universidade de São Paulo (USP), Brasil

DOI: https://doi.org/10.18472/cvt.21n1.2021.1861

janainacostasousa@usp.br

Redalyc: http://www.redalyc.org/articulo.oa?

Edegar Luis Tomazzoni

Universidade de São Paulo (USP), Brasil

eltomazzoni@usp.br

\section{Resumo:}

Nome dos mais respeitados entre os intelectuais da época, figura importante no cenário cultural brasileiro, Mário de Andrade foi, ao lado de amigos, mentor do Movimento Modernista e pesquisador de muitas categorias que se referissem ao Brasil. O objetivo deste artigo é analisar a relação entre turismo e cultura, presente na obra literária de Mário de Andrade. Especificamente, objetivam-se discutir a metodologia aplicada pelo autor e apresentar contribuições para a teoria e a prática do turismo nacional contemporâneo. A metodologia consiste em análise sistemática da bibliografia. Nas discussões metodológicas do trabalho, de natureza qualitativa, exploratória e abordagem de análises bibliográfica e de conteúdo, enfatiza-se o próprio método etnográfico do poeta, que descreve as suas impressões sobre o Brasil, com base em um diário de bordo ao longo de duas viagens ao Norte e ao Nordeste do país, entre 1927 e 1929. Verifica-se, claramente, que, ao concretizar suas viagens etnográficas, o autor exercia a prática do turismo cultural. O turista aprendiz, Mário de Andrade, é o próprio turista que faz a opção pelo turismo cultural, em seu sentido autêntico e profundo. Palavras-chave: Mário de Andrade, Viagem Etnográfica, Turismo, Cultura.

\section{Abstract:}

One of the most respected intellectuals of the time, an important figure in the Brazilian cultural scene, Mário de Andrade was, alongside friends, mentor of the Modernist Movement and researcher of many categories that referred to Brazil. The purpose of this article is to analyze the relationship between tourism and culture present in the literary work of Mário de Andrade. Specifically, the aim is to discuss the methodology applied by the author and present contributions to the theory and practice of contemporary national tourism. The methodology consists of a systematic analysis of the bibliography. In the methodological discussions of the work, of a qualitative, exploratory nature and approach to bibliographic and content analysis, it is emphasized the poet's own ethnographic method, which describes his impressions about Brazil, based on a logbook, along the route of two trips to the North and Northeast of the country, between 1927 and 1929. It is clear that, when making his ethnographic trips, the author could already be practicing what today is called cultural tourism. The apprentice tourist, Mário de Andrade, is the contemporary tourist who opts for cultural tourism. The apprentice tourist, Mário de Andrade, is the tourist who makes the choice for cultural tourism, in its authentic and profound sense.

KEYworDs: Mário de Andrade, Ethnographic Travel, Tourism, Culture.

\section{Resumen:}

Nombre de uno de los intelectuales más respetados de su época, figura importante del panorama cultural brasileño, Mário de Andrade fue, junto a amigos, mentor del Movimiento Modernista e investigador de muchas categorías que se referían a Brasil. El propósito de este artículo es analizar la relación entre turismo y cultura, presente en la obra literaria de Mário de Andrade. En concreto, tiene como objetivo discutir la metodología aplicada por el autor y presentar aportes a la teoría y la práctica del turismo nacional contemporáneo. La metodología consiste en el análisis sistemático de la bibliografía. En las discusiones metodológicas del trabajo, de carácter cualitativo, exploratorio y abordaje del análisis bibliográfico y de contenido, se hace énfasis el método etnográfico del propio poeta, que describe sus impresiones de Brasil, a partir de un cuaderno de bitácora a lo largo de la ruta de dos viajes al norte y noreste del país, entre 1927 y 1929 . Es evidente que, al realizar sus viajes etnográficos, el autor practicaba el turismo cultural. El turista aprendiz, Mário de Andrade, es el turista que elige el turismo cultural, en su sentido auténtico y profundo. 
Palabras ClaVe: Mário de Andrade, Viaje Etnográfica, Turismo, Cultura.

\section{INTRODUÇÃo}

Mário de Andrade, ao concretizar suas viagens etnográficas, exercia a prática do turismo cultural. Nessa condição, o autor e poeta desejava realizar o sonho de viagem e buscava construir-se como pessoa, olhar a si mesmo e à sua cultura na cultura do outro e construir aproximações e diferenças.

A fim de entender a relevância da contribuição de sua obra para o turismo cultural, é fundamental conhecer os principais fatos de sua extensa biografia. Em razão dessa amplitude, para contextualização do conteúdo em análise, e visando a entender as suas origens e o seu processo histórico, neste artigo, mencionam-se fatos da linha cronológica do autor. A finalidade é destacar os aspectos que mais se vinculam ao objetivo de analisar o turismo cultural em sua obra.

A biografia de Mário de Andrade mostra uma figura das mais emblemáticas do cenário cultural brasileiro ${ }^{[1]}$. Poeta, pesquisador, documentarista, etnógrafo, musicólogo, professor, fomentador das artes e da cultura popular, inventor de políticas culturais, defensor e incentivador da revelação da identidade brasileira, mentor do Movimento Modernista, pesquisador de todas as categorias que se referissem ao Brasil e, ainda, um turista aprendiz (Amaral, 1979).

Em 1924, tornou-se sócio do Automóvel Club e participou da histórica viagem da "Descoberta do Brasil": visita a Minas Gerais, feita por um grupo paulista ligado ao Modernismo; denominava-se Caravana Paulista. Realizou sua segunda "viagem etnográfica" ao Nordeste do Brasil (dezembro 1928 a março de 1929). Dedicou atenção especial para o encontro com modernistas de Pernambuco, amigos como Ascenso Ferreira, Câmara Cascudo e Joaquim Inojosa. (Lafetá, 1998; Lopez In Andrade, 1976).

A viagem ao Nordeste caracteriza-se pela coleta de documentação acerca da poesia e da música folclórica. Mário de Andrade desejava realizar uma pesquisa mais sistemática em uma região que se oferecia tão rica em tradição musical popular. Dando continuidade à sua "Viagem Etnográfica" ao Nordeste, colheu documentos também sobre danças dramáticas. Iniciou suas leituras etnográficas ${ }^{[2]}$. Em 1937, projetou o Regulamento do Departamento de Cultura, contratou o casal Lévi-Strauss para ministrar curso de Etnologia em São Paulo. Enviou nova missão de pesquisa ao Norte e Nordeste. (Lopez, 2002).

Criou a Sociedade de Etnografia e Folclore de São Paulo, tornando-se seu primeiro presidente. Organizou o $1^{\circ}$ Congresso de Língua Nacional Cantada e projetou a criação do Serviço de Patrimônio Histórico e Artístico Nacional (SPHAN). (Amaral, 1979).

Mário de Andrade escreveu sobre a estética do Modernismo: “Já um autor escreveu, como conclusão condenatória, que a "estética do Modernismo ficou indefinível" [...] Pois essa é a melhor razão de ser do Modernismo! Ele não era uma estética, nem na Europa nem aqui. Era um estado de espírito revoltado e revolucionário" [...]. (Amaral, 1979, p.217).

É possível que a Semana não tenha sido o fato mais importante da cultura brasileira, como queriam alguns de seus integrantes. Mário de Andrade diria, mais tarde, que faltou, aos modernistas de 1922, um maior empenho social, seus autores colocaram a renovação estética acima de outras preocupações importantes. "Mas sabe-se que o espírito modernista destruiu um imobilismo cultural que entravava as criações mais revolucionárias e complexas, possibilitando um caminho livre à geração posterior”. (Gonzaga, 1998, p.170).

O poeta mostrava-se hesitante quanto a opções estéticas sustentadas pelos seus companheiros de jornada Oswald de Andrade e Tarsila do Amaral: "queríamos ser progressistas, reformadores, cubistas, fomos buscar o que não era nosso, imitamos sem altivez, copiamos sem engenho [...]”. (Katinsky, 2002, p.66).

O período construtivo do movimento modernista começou depois da Semana de Arte Moderna, quando as propostas passaram a ser sistematizadas e colocadas em prática. "Pode-se citar como um dos resultados a campanha intensa de divulgação de novas ideias através de revistas, como, por exemplo, a revista Klaxon, que 
surge logo após a Semana, com campanha em todo o país”. (Rezende, 2002, p.74). Ficou clara a valorização do nacional, visão que foi implantada a partir do desejo da construção de uma representação do novo Brasil.

Por sua irradiação cultural, a projeção da Semana de 1922 foi muito além de seus objetivos iniciais: além da década de 1920, atravessou a década de 1930 e se prolongou, fazendo com que até hoje nos beneficiemos com a abertura obtida. Dentre suas contribuições históricas, está o marco do nascimento de um Brasil contemporâneo, quando os problemas da cultura passaram a ser encarados em conexão com o conjunto da vida social. (Amaral, 1979; Katinsky, 2002; Rezende, 2002).

O objetivo deste artigo é analisar a relação entre turismo e cultura, presente na obra literária de Mário de Andrade. Especificamente, objetivam-se discutir a própria metodologia aplicada pelo autor e apresentar contribuições para a teoria e a prática do turismo brasileiro contemporâneo.

Mário de Andrade buscava uma identidade nacional, a partir do descobrimento e da vivência do desconhecido. E não bastava só vivenciar, as expedições eram sempre documentadas, a fim de se fazer um estudo etnográfico do país. Além de constatar as tipologias motivacionais do turismo, ou das motivações de quem decide por fazer turismo, por meio de roteiros de viagens, verifica-se, portanto, o rigor metodológico das suas pesquisas. A expressão "viagem etnográfica” era empregada para especificar a natureza de suas excursões. Reitera-se a necessária contextualização de seus estudos no campo teórico do turismo, considerando-se, também, a aplicação de sua produção científica e social à atividade turístico-cultural. É essa, portanto, uma das contribuições deste artigo.

\section{Discussões METODOLÓGICAS}

Apresentam-se algumas reflexões, na sequência das anteriores, em relação à relevância da pesquisa e aos seus procedimentos metodológicos. As categorias analíticas, mais do que denotadas no próprio texto do escritor e etnógrafo das viagens, são evocadas pelas descrições dos cenários e das realidades de vida das populações dos lugares por ele visitados (Bardin, 2011; Minayo, 2001; Moraes, 1994). Se, no texto de Mário de Andrade, o método etnográfico consubstancia-se pelas narrativas, relatos, descrições, explicações e esclarecimentos dos contextos analisados pelo pesquisador, essas categorias não estão somente implícitas; são inerentes e evidentes no seu conteúdo textual.

O autor é autossuficiente, não somente porque sua obra é escrita de forma erudita, refinada, simples e clara, mas porque é Mário de Andrade, a referência, que se expressa com riqueza de detalhes. Se ele é o intelectual, o antropólogo, o revelador da alma brasileira é, portanto, pesquisador do turismo brasileiro, com base em visões da autenticidade e das identidades únicas.

Essas são razões pelas quais se enfatiza que esta discussão metodológica tem o enfoque de separar os procedimentos de pesquisa do artigo dos procedimentos de pesquisa do autor Mário de Andrade, mostrando, ao mesmo tempo, a forte imbricação entre ambos os procedimentos. Por se tratar de objetivo de analisar o turismo cultural em sua obra, representada essencialmente pela publicação bibliográfica $\mathrm{O}$ Turista Aprendiz, os critérios para a produção textual deste artigo foram os temas que constituem a estrutura deste texto, desde os aspectos biográficos, até os relatos, as interpretações das viagens etnográficas e as suas contribuições para o conhecimento do turismo cultural.

Como desdobramentos, para as respectivas seções do artigo, os critérios teórico-conceituais das categorias analíticas específicas, para análises mais minuciosas, são os significados de turismo cultural, vinculados à conceituação de viagens etnográficas, em articulação, também, com a definição de turismo cultural. As diversas formas de expressão e de manifestação dos grupos sociais e as relações destes com o turista aprendiz categorizam-se em: hábitos, costumes, tradições, modos de vida, processos de produção artesanal e interação com o meio ambiente.

Outro critério categorial é o conjunto de elementos que compõem os fatores motivacionais e decisórios das realizações das viagens etnográficas pelo autor pesquisador. A etnografia literária é o método dos estudos e da 
produção cultural em turismo de Mário de Andrade, na condição de turista cultural aprendiz, que assimila, reconhece e ensina as identidades locais e os valores dos grupos étnicos nacionais e de suas mais verdadeiras e singulares expressões.

$\mathrm{O}$ artigo enquadra-se nos padrões da metodologia científica, por meio da análise do conteúdo representativo, com base na fundamentação conceitual de turismo cultural, ao mesmo tempo em que se identificam os procedimentos técnico-metodológicos das viagens etnográficas de Mário de Andrade. A própria obra do poeta e escritor, que é o etnógrafo das viagens, o torna reconhecido como a referência de turismo cultural para as finalidades deste trabalho.

Enfim, a visão cultural e etnográfica está contida no ciclo teórico-empírico produtivo da obra de Mário de Andrade. Estão implícitos e evidentes os conceitos de turismo e de turismo cultural, que abrangem a própria definição de cultura e de suas modalidades expressivas, como o folclore e o patrimônio. Mário de Andrade tinha um propósito ao ir a campo para realizar as suas investigações: valorizar a riqueza cultural do Brasil.

O propósito é aquilo que se define, no método científico, como o objetivo, que significa o sentido maior das suas missões: reunir conteúdos e fundamentações, que transcendessem a tarefa de mostrar produtividade acadêmica, por meio de indicadores, seja de publicações, seja de trabalhos técnicos. Na base, porém, desse propósito investigativo, havia o propósito central, motivador, a razão essencial das viagens etnográficas: conhecer a revelar a identidade e a diversidade cultural do Brasil. Para o conhecimento e a revelação dos valores nacionais, a viagem foi a estratégia metodológica, que lhe proporcionou os contatos presenciais e as vivências experienciais com as pessoas dos diversos lugares de percurso e de permanência.

A etnografia está presente no processo de interação e de observação direta e atenta das práticas cotidianas e das relações de acolhimento dos núcleos visitados e nas interações do intelectual com as pessoas, por meio dos diálogos e dos olhares observadores. Pensar nesse processo produtivo de $\mathrm{O}$ Turista Aprendiz foi argumento para seleção das leituras e redação analítico-interpretativa do texto deste artigo, priorizando-se a ideia de que a etnografia pressupõe "viajar para outras culturas".

Não há etnografia sem atenção ao desconhecido, ao diferente, sem o escopo da descoberta e da confirmação de expectativas. O método etnográfico confunde-se com o método turístico, no sentido de ir ao encontro e de ter contato direto com outras identidades e manifestações culturais.

Para a produção textual deste artigo, as leituras da bibliografia foram realizadas com base em critérios que identificassem o perfil de cientista, de idealista e visionário, a fim de verificar como Mário de Andrade produziu a sua obra e revelou, com base no seu dom literário, etnográfico e turismológico, a riqueza da diversidade e da intensidade da cultura brasileira.

Nesse processo, verificou-se como ele organizou as próprias viagens, planejou os roteiros de suas pesquisas, fez os registros de campo e as análises. Assume-se, como princípio fundamental, que Mário de Andrade foi pesquisador do turismo por essência, a fim de entender como as suas incursões foram modelos pedagógicos para os interessados no significado da viagem para a humanização cultural e a edificação espiritual das comunidades locais, dos turistas e do próprio Brasil.

\section{O TURISMO CULTURAL E O SEU SIGNIFICADO}

Este tópico apresenta os conceitos de turismo cultural, a fim de fundamentar o objetivo de analisar a sua relação com a produção etnográfica de Mário de Andrade. Inúmeros são os motivos que levariam um indivíduo a manifestar o desejo por viajar, do deslocamento. $\mathrm{O}$ ato da viagem agrega vários desejos e prazeres, como o gastronômico, o cultural, o intelectual, o aventureiro, o esportivo, o descobridor, entre outros (Barretto, 2007; Trigo, 2001). Esses prazeres podem ser inconscientes ou predestinados. Os meios de comunicação e, no caso específico, a literatura, favorecem essa busca, essa curiosidade.

Compreender a cultura de um povo expõe a sua normalidade sem reduzir a sua particularidade (Geertz, 1989). 
$\mathrm{Na}$ condução das relações entre material e imaterial, o autor e teatrólogo, Oswald Barroso, nos diz que:

Ações humanas, gestos, toques, movimentos, posturas do corpo, que não têm a solidez das fortalezas, nem a grandiosidade das catedrais, podem, porém, restar preservadas na nossa memória corporal. Sons, passos, ritmos, jogos, brincadeiras, formas de andar, sentar ou falar são sutilezas que se desfazem tão logo cumprem seu trajeto, não é possível tombá-las como castelos ou obras de arte, mas, quando se repetem através dos séculos, ganham registro no cérebro humano. Falas, cantos, contos, ritos, mitos, lendas e narrativas, versos feitos, advinhas, danças, festas, frases musicais, folguedos, modos de colocar o corpo e a voz, são feitos que se completam. Porém, o tempo necessário à gestação de muitos deles atravessa séculos e incorpora a colaboração de numerosas gerações. Procedimentos de alimentação e cura, modos de bater tambor ou tocar sinos, de requebrar os quadris, de comunicar-se com deuses ou com a natureza, maneiras de ver as cores, de ler as estrelas, de confeccionar objetos, de memorizar, são tesouros intangíveis joias imateriais que o povo acumula e passa aos filhos como um legado. Tais ações, tornadas tradicionais, não apenas expressam nosso modo de ser enquanto povo, como revelam nossa universalidade, porque, à medida que afirmam nossa singularidade, nos ligam a outras gentes, tornando-os infinitos e eternos. Daí por que nos encantam, nos causam estranha empatia, falam à alma, ao corpo e ao espírito. Daí por que o mais simples e humilde indivíduo pode tomar ares de rei quando dança o Maracatu. Daí por que um analfabeto torna-se mestre, quando detém o segredo de um ofício ou de uma dança ancestral. (Barroso, 2002, p.14).

Bem antes da ciência e da academia, o ser humano observava o mundo e tirava lições, aprendia e acumulava saber. Cada povo criou, assim, um modo de viver e raciocinar, mas também de buscar utopias, que aos poucos foi se inscrevendo em seu próprio corpo, como também em suas ações mais recorrentes.

A exemplo dos prédios, tais ações podem ser destruídas tanto pela ausência como pelo mau uso. Degradamse pelo abandono, mas também pela perda de significação, devido a modismos, repetições mecânicas e exaustivas (Gastal \& Castrogiovani, 1999). Constituem patrimônio que, para ser preservado, necessitam não apenas de inventários, registros, proteções e estímulos; como exige, principalmente, estar gravado nos músculos, nos sentidos, no pensamento e no coração de quem o criou. Preservá-lo é usá-lo, praticá-lo, mas também renová-lo e juntá-lo a nossa contribuição, tornando-o nosso, vivo e contemporâneo.

Para a valorização dessas manifestações e identidades, a contribuição do turismo é inegável. O turista é movido pela curiosidade e expectativa de compreensão das diferenças culturais entre sociedades. O desejo por adquirir novos conhecimentos motiva o relacionamento sociocultural (Beni, 2001; Wahab, 1991; Tribe,1991; Swarbrooke \& Horner; 2002; Buhalis \& Leung, 2018). Viajar significa também retornar do destino visitado e ver valores da própria cultura, que, até então, não eram percebidos.

Quando visto sob o aspecto abstrato, o turismo revela elementos que remetem às interações e aos relacionamentos individuais e grupais, à compreensão humana, aos sentimentos, motivações, ao prazer, ao ócio e à recompensa (Richards, 2005; Yázigi, 1998). Proporciona a troca entre os povos, juntamente com a descoberta de novos horizontes, assimilando outras culturas e despertando, nos que buscam a atividade, enquanto viajantes, a curiosidade das divergências de seu local de origem.

O viajante encontra o outro nas suas mais diversas formas de expressão: na literatura, no folclore, nas artes visuais, na música, na dança, na gastronomia, entre outras. Todas estas formas de expressão estão associadas a modos de vida e a maneiras de sentir e pensar cotidianas, de resolver problemas, de construir teias de relacionamentos. (Krippendorf, 2001; Tomazzoni, 2009). Ser um turista supõe disponibilizar-se para esses desafios, choques e estranhamentos, colocando a si as suas crenças e maneiras de ser em profundo questionamento.

\section{Mário de Andrade: o tUrista APrendiz}

Apresenta-se, a seguir, a descrição das viagens etnográficas de Mário de Andrade, conforme a sua obra, finalizando com a associação ao turismo cultural e ao turista que o pratica. O conteúdo deste tópico é embasado no texto de Lopez (1976), "Viagens Etnográficas" de Mário de Andrade, no livro do próprio escritor, O Turista Aprendiz. 
Mário de Andrade, a partir de suas viagens etnográficas pelo Brasil, foi um turista em seu ato, um aventureiro na posição de viajante etnógrafo que, rondando o limite das culturas e linguagens humanas, percorreu um elevado número de quilômetros, acumulando e coletando informações. A curiosidade do viajante junta-se à minúcia do pesquisador. Seus anos de estudo e as viagens o fizeram descobrir, no próprio país, as verdades e o conhecimento que a geração que lhe foi contemporânea costumava buscar e reconhecer apenas em experiências europeias.

Poeta, romancista, crítico de música e de arte, com olhar atento e treinado, fotógrafo, epistológrafo e musicólogo brasileiro, professor, documentarista, fomentador das artes e da cultura popular, Mário de Andrade tem sua atuação intelectual vista como fundamental na cultura brasileira do século XX. Foi, ao lado de amigos, mentor do Movimento Modernista, a partir da realização da Semana da Arte Moderna, e foi, principalmente, um entusiasta do Brasil, de seus costumes e do seu folclore, razão pela qual decidiu vivenciar o que o país oferece, em várias viagens etnográficas, muitas delas, em companhia de amigos como Oswald de Andrade, Tarsila do Amaral, D. Olívia Guedes Penteado e demais expoentes das artes no Brasil (Lopez, 1976).

Para o modernista Mário de Andrade, empenhado em entender a realidade brasileira dentro de um quadro latino-americano e em traçar, na medida de suas possibilidades, as coordenadas de uma cultura nacional, tomando o folclore e a cultura popular como instrumentação para o seu conhecimento do povo brasileiro, foi muito importante unir a pesquisa de gabinete e a vivência de vanguardista metropolitano ao encontro direto com o primitivo, o rústico e o arcaico, que, em seu enfoque dialeticamente dinâmico, puderam lhe valer como indícios de autenticidade cultural. (Lopez, In Andrade, p.15, 1976).

Assim, percebe-se que a valorização do nacional já existe para o jovem professor do Conservatório Dramático e Musical de São Paulo. A década de 1920, sob o impacto das ideias propagadas na Semana de Arte Moderna, marcou o empenho de Mário de Andrade em conhecer de perto a cultura popular brasileira.

A primeira viagem da caravana paulista esteve formada pelos modernistas de São Paulo e seus amigos, composta por Tarsila do Amaral, Mário de Andrade, Oswald de Andrade e seu filho Nonê (Oswald de Andrade Filho), D. Olívia Guedes Penteado, Paulo Prado, René Thiollier e Godofredo da Silva Telles; ocorreu em 1924, aproveitando a visita ao Brasil do poeta francês Blaise Cendrars, e teve como destino o Estado de Minas Gerais (Lopez, 1976).

Essa viagem, porém, não se caracterizou como etnográfica e sim como um percurso pelo interior mineiro, possibilitando o contato com o povo, vindo a ser denominada de "viagem da descoberta do Brasil", que, conforme destaca Lopez (1976, p.16), provoca um amadurecimento no projeto nacionalista dos modernistas, fazendo com que a ênfase, inicialmente sobre o lado estético, ganhasse abrangência para o lado de um projeto ideológico. O contato direto com essa parcela do povo brasileiro fez com que todos observassem os processos de criação popular mais livres e mais condizentes com as nossas condições e, em alguns pontos, até mesmo apresentando coincidência com propostas europeias.

A partir de leituras e dos bons resultados da "viagem da descoberta do Brasil" a Minas Gerais, Mário de Andrade sentiu-se inclinado a conhecer e a vivenciar as culturas do Norte e Nordeste do Brasil, dando início, então, às suas viagens etnográficas, nas quais faria coleta de documentações, registrando as suas impressões sobre o país. A curiosidade por essas regiões brasileiras se deu por serem as mesmas ricas fontes de tradição e cultura popular. E Mário de Andrade, desbravador do Brasil e estudioso do folclore, não aceitaria o descaso para com seus valores. Acreditava ser o folclore uma ciência social:

Nessa época, é necessário que se ressalte, nosso escritor, que estuda o Folclore e recolhe documentos, já não considera o Folclore como uma disciplina isolada, autônoma, colocando-o muito lucidamente enquanto ciência social, como Etnografia, pois não dispunha de meios para diferenciar as atribuições da Antropologia cultural, da Etnografia e da Etnologia. Assim fazendo, está se insurgindo contra uma posição elitista de seu tempo que congelava o Folclore, dissociando-o dos demais fenômenos da sociedade e reduzindo-o à valorização do pitoresco. (Lopez, in Andrade 1976, p.16). 
Em maio de 1926, Mário escreveu ao amigo Manuel Bandeira, comentando seus anseios por conhecer o Norte; na verdade, o destino seria a região Nordeste, mas já havia, naquela época, a generalização de Norte feita pelos paulistas; porém, a viagem não se concretizou.

"Pois é, estou de viagem marcada pro Norte. Vou na Bahia, Recife, Rio Grande do Norte, onde vive um amigo do coração que, no entanto, nunca vi pessoalmente, o Luís da Câmara Cascudo. É um temperamento estupendo de sujeito, um coração de ouro". (Andrade,1976, p.17).

No ano seguinte, a caravana da descoberta do Brasil partiu rumo à Amazônia. A viagem, desta vez, foi por ele intitulada de "Viagem pelo Amazonas até o Peru, pelo Madeira até a Bolívia e por Marajó até dizer chega". E Mário outra vez escreveu ao amigo Manuel Bandeira, confiando seu entusiasmo e suas hesitações:

Estava planejando dar um pulo até Pouso Alegre ver você, porém, de supetão, de domingo para cá minha vida deu um saltomortal danado. Creio que vou pro norte no mês que vem, numa bonitíssima duma viagem. Dona Olívia faz tempo que vinha planejando uma viagem pelo Amazonas adentro. E insistia sempre comigo para que fosse no grupo. Eu ia resistindo, resistindo e amolecendo também. Afinal, quando tudo quase pronto, resolvi ceder mandando à merda esta vida de merda. Vou também. Isto é, ainda não sei bem se vou, só falta saber o preço da viagem. Se ficar aí por uns quatro contos, vou, se ficar pra cima de cinco não vou. Tenho que emprestar dinheiro pra ir e isso vai me deixar a vida bem difícil depois e os projetos no tinteiro. (Andrade, 1976, p.17).

A resistência inicial à viagem não foi sustentada por Mário de Andrade que, na mesma carta ao amigo Manuel Bandeira, apresentou o programa e os prováveis companheiros de viagem:

Vamos pelo Loide Brasileiro, parando de Porto em Porto até Manaus. De lá subimos o Amazonas já com tudo determinado pelo Geraldo Rocha para pararmos em todas as partes interessantes; continuamos pelo Madeira e vamos parar na Bolívia. Depois não sei como é a volta... (Andrade,1976, p.18).

Percebe-se, no escritor, a empolgação com a ideia da viagem mais evidente que as resistências a tal deslocamento. Conheceriam grande parte da Amazônia, chegando ao Peru e à Bolívia, e encontrariam, na passagem pelo Nordeste, os amigos Ascenso Ferreira, Câmara Cascudo e Joaquim Inojosa. Outro atrativo que deixou Mário de Andrade muito feliz foram as datas escolhidas para a viagem: 13 de maio a 15 de agosto, pois era neste período que aconteciam as danças dramáticas do Norte, por ocasião das chuvas. Assim, a caravana, que tinha por objetivo fazer uma viagem etnográfica, poderia assistir aos ensaios e apresentações dos grupos populares.

A viagem à Amazônia foi marcada pela preocupação etnográfica, na procura pelo entendimento das particularidades do Brasil, através da observação da vida do povo. A Amazônia era uma antiga atração, valorizada por Mário de Andrade desde seus primeiros escritos. Segundo Lopez, o poeta acreditava ser a Amazônia "a sede de uma vivência tropical, marcada pelo ócio criador" (in Andrade 1976, p.17).

Mário de Andrade partiu de São Paulo para encontrar-se com os companheiros no Rio de Janeiro e lá tomarem o navio Pedro I, do "Loide Brasileiro". Alguns imprevistos aconteceram, a começar pela tão esperada comitiva que havia se reduzido a D. Olívia Guedes Penteado, dama da aristocracia cafeeira, mecenas dos modernistas e personalidade de relevo em São Paulo, que era acompanhada pela sobrinha, Margarida Guedes Nogueira, e por Dulce do Amaral Pinto, filha de Tarsila do Amaral, e ele, único cavalheiro. Apesar desse desaponto, a comitiva partiu e livrou-se de aborrecimentos com protocolos, uma vez que viajavam recomendados aos presidentes dos Estados enquanto "Comitiva da Rainha do Café".

O poeta se dizia turista aprendiz, pois, ao contrário de seus amigos modernistas, "não conhecia 'Oropa, França e Bahia' - nem Paris (!)”. E descreveu essa sua condição no diário de bordo durante a viagem à Amazônia:

É incrível como vivo excitado, se vê que ainda não sei viajar, gozo demais, concordo demais, não saboreio bem a minha vida. Estas notas de diário são sínteses absurdas, apenas para uso pessoal, jogadas num anuariozinho de bolso, me dado no Loide Brasileiro, que só tem cinco linhas para cada dia. As literatices são jogadas noutro caderninho em branco, em papéis de carta, costas de contas, margens de jornais, qualquer coisa serve. Jogadas, sem o menor cuidado. Veremos o que se pode fazer com isso em São Paulo. (Andrade, 1976, p.29). 
Segundo Lopez (in Andrade 1976, p.40), os relatos e as impressões transcritos para um diário de bordo eram feitos com a intenção de transformar-se em um futuro "livro de viagens", a que chamaria de O Turista Aprendiz, caracterizando um novo gênero, proposto por Mário de Andrade: a narrativa de viagens, proposta de interesse dos modernistas, significativamente marcada por Pathé-baby, livro de Alcântara Machado, que valorizava as narrativas cronista e ficcionista.

\section{Os diários das viagens etnográficas de Mário de Andrade}

Mário, modernista e também nacionalista, produzirá ficção a partir da própria realidade experimentada ou observada, fazendo questão de explorá-la em dois aspectos: o real e o ficcional, partindo desse mesmo real e bastante auxiliado pelo seu senso crítico e sua concepção de realidade sul americana, que lhe fizeram entender que "dentro de uma ótica europeia, marcada pelo racionalismo, acostumada a um mundo tecnicista, nossa realidade seria o maravilhoso instaurado em sua peculiaridade, sensível a uma abordagem surrealista" (Lopez, in Andrade, 1976, p.40). A descoberta do maravilhoso faz com que o autor trabalhe a narração, evitando a descrição do que já fora repetido e documentado.

Neste diário de bordo, percebe-se a influência do Modernismo nos escritos - já no prefácio identificase o bom humor que foi peculiar ao escritor e ainda sua sensibilidade, de quando relatou suas sensações em um ambiente estranho, que são próximas, intensas e incapazes de serem destruídas. "Mais advertência que prefácio. Durante esta viagem pela Amazônia, muito resolvido a ... escrever um livro modernista, provavelmente mais resolvido a escrever que a viajar, tomei muitas notas como vai se ver" (Andrade, 1976, p.49).

A partir desse depoimento, entende-se que Mário de Andrade não tinha pretensões de que o seu diário de bordo fosse transformado em um guia turístico, tampouco tivesse grande relevância no conjunto de sua obra. Esse diário tinha um aspecto confessional, detectado na forma como o cronista narrou suas emoções, rememorando os sentimentos de seus dias.

Agora reúno aqui tudo, como estava nos cadernos e papéis soltos, ora mais, ora menos escritos. Fiz apenas alguma correção que se impôs na cópia. O conjunto cheira a modernismo e envelheceu bem. Mas pro antiviajante que sou, viajando sempre machucado, alarmado, incompleto, sempre se inventando malquisto do ambiente estranho que percorre, a releitura destas notas abre sensações tão próximas e intensas que não consigo destruir o que preservo aqui. Paciência..." (Andrade, 1976, p.49).

Valiosas informações, recolhidas na viagem de 1927 à Amazônia e na viagem etnográfica de 1928/1929 ao Nordeste, não foram anexadas à versão definitiva de $\mathrm{O}$ Turista Aprendiz, pois, como se sabe, Mário de Andrade costumava inutilizar as primeiras redações de textos já definitivos. Porém, em um processo que envolvia unicamente a sua produção, fazia questão de manter todo o material de pesquisa e documentaçãovária, que recolhera ao longo de sua vida, intactos em seu arquivo; hoje, sob responsabilidade da Universidade de São Paulo, por meio do Instituto de Estudos Brasileiros (Lopez in Andrade, 1976).

A segunda viagem, desta vez com destino ao Nordeste, foi realizada no período compreendido entre dezembro de 1928 a março de 1929, sendo denominada de viagem etnográfica. Para essa viagem, Mário preparou-se pesquisando junto aos discos, livros, fichários e piano, agregando pesquisa e criação, buscando de maneira incansável as fontes da cultura brasileira. A viagem desta vez foi feita com as economias necessárias e Mário partiu sozinho do Rio de Janeiro a bordo do navio Manaus.

Estando novamente livre de protocolos e ainda dono do seu tempo, pode visitar os lugares desejados como Pernambuco, Alagoas, Rio Grande do Norte e Paraíba, e conviver com seus amigos Ascenso Ferreira, Cícero Dias e Antônio Bento de Araújo Lima. O roteiro foi estabelecido tendo em mente que esses amigos pudessem lhe dar as indicações de informantes e endereços precisos que serviriam para as suas pesquisas. Partindo em 
dezembro, visava, sobretudo, os reisados e pastoris do Natal e início do ano. Toni (2002, p.78) destaca a concentração do poeta na transcrição de cantigas, bem como nas coreografias e indumentárias.

O poeta não tinha prática na transcrição imediata das melodias que pretendia registrar e, sem dinheiro para comprar um gravador (sic), viajou só com lápis e papel, daí a necessidade constante de um piano para reproduzir o que ouvia antes de anotar no pentagrama. Processo longo e passível de críticas, pois os cantadores eram submetidos ao teclado e sabe-se que estes informantes geralmente não cantam em seguida da mesma maneira.

Trabalhou arduamente, principalmente, na Paraíba e no Rio Grande do Norte, recolheu um sem-número de documentos musicais, e assistiu a ensaios e representações de danças dramáticas. Estudou a religiosidade popular, o Catimbó, a música de feitiçaria, e passou o carnaval em Recife.

Conheceu figuras folclóricas em cada região, dando destaque ao paraibano Chico Antônio, cantador que permanecia sempre acompanhado de seu instrumento, o ganzá, e que chamou a atenção do poeta pela sua capacidade de interpretação e criação. Agregando suas vivências de viajante observador às suas atividades literárias, Mário de Andrade pretendia fazer desse homem simples do sertão, personagem de seu romance Café, porém abandonou o projeto e transformou-o no protagonista de Vida de Cantador (Lopez in Andrade, 1976, p.20).

Percebe-se a sensibilidade do poeta no entendimento de que esse simples sertanejo poderia não ter os estudos de um compositor erudito, mas a sua essência de cantador e a intimidade com o ganzá, seu instrumento musical, era latente e certamente seria transmitida aos filhos como legado, como riqueza e tradição familiar. $\mathrm{O}$ trajeto percorrido nesta viagem fazia parte de uma estratégia para organizar seu "nacionalismo".

Sentindo que não tinha forças suficientes pra me universalizar, sem aquele gênio, ah! Que me importa como brasileiro ao mundo, doutra forma me abrasileirei: dentro da ordem das minhas tendências artísticas, me fiz brasileiro para o Brasil. Resolvi trabalhar a "matéria" brasileira, especificá-la, determiná-la o quanto em mim [sic] e na complexidade dele. O caso lingüístico não é senão um dos muitos corolários dessa realização de mim. Digo "de mim” e não do Brasil, porque sabia muito conscientemente desde o princípio, que se tratava de dar a minha contribuição pessoal, e não, com o meu serzinho minúsculo realizar o sentido e a imagem do Brasil. Não havia folclore musical brasileiro. Fiz folclore musical brasileiro. Não havia crítica de arte em São Paulo, e a pouca brasileira existente era mais que péssima. Fiz crítica de $\operatorname{arte}^{[3]}$.

A viagem ao Nordeste rendeu, além da transformação do diário de bordo nas crônicas de $\mathbf{O}$ Turista Aprendiz, outros resultados significativos para a produção literária de Mário de Andrade. A reunião de farto material de pesquisa sobre danças dramáticas, sobre melodias em torno da temática do bumba-meu-boi, sobre música de feitiçaria, religiosidade popular, crenças e superstições, poesia popular, teria seus elementos aproveitados em artigos, ensaios e conferências ao longo de sua vida. Viajando pelo Nordeste, Mário de Andrade acreditou que havia ainda um Brasil por descobrir e valorizar, para ser entendido enquanto vida e cultura do povo.

Essa dimensão, a da pesquisa etnográfica e a do enfoque sociológico, revelará as danças dramáticas, o catimbó e procurará analisar as condições de vida da região, numa perspectiva nova que deseja abandonar a caracterização do regional através do exótico e do pitoresco, porque estará preocupada com as relações de produção e com as classes sociais. (Lopez in Andrade, 1976, p.41).

Ambas as viagens etnográficas possuem, ainda, importante documentação fotográfica, principalmente a viagem de 1927 à Amazônia. Mário de Andrade fotografou exaustivamente, registrando não somente seu dia-a-dia junto aos companheiros, como também direcionando seu olhar fixo e observador para os aspectos da paisagem, tipo humano, formas de trabalho, meios de transporte e arquitetura.

Mário de Andrade acreditava que havia muito o que conhecer, o que viajar, o que visitar e, ao narrar suas impressões sob forma de diário, o fez com muito humor, fantasia e, acima de tudo, registro jornalístico dos 
acontecimentos. A observação dos costumes do povo, suas crendices, danças, cantos e condições de vida foi realizada, não somente ao sabor do modernismo, mas embasada pelo movimento modernista.

\section{CONSIDERAÇÕES FINAIS}

A curiosidade de Mário de Andrade por conhecer as regiões Norte e Nordeste era dada pelo entendimento de serem ricos "repositórios" de tradição e de cultura popular, que ele desejava vivenciar diretamente para realizar estudos etnográficos a partir de documentação das manifestações e das criações populares, registrando ainda seu interesse pela arquitetura e pelo imaginário sacro e sua preocupação com as condições de vida e trabalho do povo. $\mathrm{O}$ folclore, principalmente, o folclore musical, foi uma das frentes de estudo deste intelectual, que acreditava e defendia a teoria de tratá-lo como uma ciência e não reduzir à valorização do pitoresco, como comumente era tratado.

Na década de 1920, o Brasil presenciou um momento de busca pela sua nacionalidade, era o Movimento Modernista, em que intelectuais, poetas, artistas plásticos e demais componentes da classe artística acreditavam que era preciso uma valorização do nacional para depois ser cosmopolitas, reconheciam a alienação vinda da moda da cultura francesa e de toda uma civilização construída aos moldes europeus.

Por isso, esse grupo decidiu partir em busca do Brasil desconhecido. Acreditavam que nada melhor que o contato direto com o povo para se fazer entender as nossas origens. Buscavam também uma tentativa de compreendê-las para assim optarem por assumir uma verdadeira identidade A grande maioria dos modernistas era de viajantes profissionais, o único que não tinha grandes experiências em viagens era Mário de Andrade, razão pela qual se intitulava "turista aprendiz". Um turista sempre disposto a vivenciar intensamente os locais por onde passava, desprovido de preconceitos ou pré-julgamentos.

Como viajante-observador, Mário de Andrade fez, nas suas andanças, diferentes análises da cultura brasileira, dedicando atenção especial ao folclore e suas manifestações populares. Pode-se dizer que esse é o turismo cultural, e o turista que hoje faz esta opção poderia ser o turista aprendiz Mário de Andrade da década de 1920, buscando sempre um maior conhecimento, no caso específico, do Brasil.

A preocupação de Mário de Andrade em inventariar o patrimônio também recebeu influência das viagens por ele vividas. A partir delas, foram estabelecidas por ele as diretrizes para o que hoje denominamos patrimônio imaterial. Como sabemos, é dele o anteprojeto que deu origem, em 1936, ao SPAN - Serviço de Patrimônio Artístico Nacional, hoje IPHAN - Instituto do Patrimônio Histórico e Artístico Nacional.

Mário de Andrade acreditava que reconhecer e registrar os saberes, as celebrações, as expressões, os lugares, valorizando a contribuição da população para a formação de uma identidade nacional, era nosso dever. Por meio desse registro, teríamos a oportunidade de resgatar e reconhecer a produção artística, literária, musical e de outras manifestações e criações da nossa população.

O registro é memória e atesta a percepção sobre patrimônio cultural. Sendo a memória de fundamental importância aos habitantes de uma localidade. Para Le Goff,

(...) é a memória dos habitantes que faz com que eles percebam, na fisionomia da cidade, sua própria história de vida, suas experiências sociais e lutas cotidianas. A memória é, pois, imprescindível na medida em que esclarece sobre o vínculo entre a sucessão de gerações e o tempo histórico que as acompanha. Sem isso, a população urbana não tem condições de compreender a história de sua cidade, como seu espaço urbano foi produzido pelos homens através dos tempos, nem a origem do processo que a caracterizou. Enfim sem a memória não se pode situar na própria cidade, pois perde-se o elo afetivo que propicia a relação habitante-cidade, impossibilitando ao morador de se reconhecer enquanto cidadão de direitos e deveres e sujeito da história. (Le Goff apud Bittencourt, 1997, p.139).

Essa perda de referenciais históricos, pautados na memória da cidade, nos dá a estranha sensação de que somos estrangeiros em nossa própria terra. Sem a memória, não encontraremos mais os ícones, símbolos e lembranças que nos unem à cidade e, assim, nos sentiremos deslocados e confusos (Oriá apud Bittencourt, 2003, p.139). 
Os estudos de Mário de Andrade buscaram uma melhor compreensão dos bens imateriais, que são tão importantes para a formação de nossa identidade. O seu legado serve de inspiração, até os dias atuais, para artistas e pesquisadores que almejam retratar melhor o povo brasileiro.

Observa-se que o conceito de cultura para Mário de Andrade é muito particular, em razão de analisar também a questão de implementação de políticas públicas para a cultura. Não é, portanto, um conceito etnográfico ou sociológico. A concepção de nacional antes de Mário de Andrade, eram os modelos estrangeiros. O nacional era decadente.

Conclui-se que não foram somente as viagens para fora de seu estado natal que se tornaram ambientes de criação ou de inspiração para as suas obras literárias. Foi na própria capital que Mário de Andrade escreveu obras importantes, como Pauliceia Desvairada. Trata-se de cenário turístico-cultural dinâmico, que pode ser conhecido e analisado atualmente, à luz da viagem literária do autor, ainda que as viagens realizadas a Minas Gerais, à região Norte e à região Nordeste sejam os principais destinos para que Mário de Andrade produzisse as referências de turismo etnográfico.

Com este trabalho, acredita-se que os escritos do poeta têm grande importância para os estudiosos do turismo. Entende-se que hoje há um turista contemporâneo que busca em suas viagens um aprendizado intelectual; esse turista é também um observador atento que, muitas vezes, em suas viagens, busca o registro fotográfico de maneira cuidadosa e especial para documentar as suas vivências no período viajado. $O$ turista aprendiz, Mário de Andrade, é o próprio turista cultural por essência.

Não se pode pensar em uma teoria de turismo cultural sem conhecer os atores envolvidos em sua produção. Mário de Andrade, com a sua referência geográfica e intensa dedicação ao campo turístico, contribuiu tanto para a sua obra como para a de outros autores que tratam de viagens de conhecimento do Brasil. (...) o certo é que jamais neguei as tradiçóes brasileiras, as estudo e procuro continuar a meu modo dentro delas (Andrade, 1976).

A identidade de modernista era incômoda no viajante que queria conhecer de perto as tradições brasileiras, dizendo para si mesmo que nunca as tinha negado (Travassos, 1997, p.9). A coleta de dados feita por Mário de Andrade e o espírito das épocas - categoria por ele utilizada, nos mostram a dimensão simbólica da vida social como objeto inseparável da prática social.

É absolutamente inquestionável, portanto, que a abrangência e a profundidade de seus estudos e publicações são conteúdos fundamentais para enriquecer o real conceito de turismo cultural brasileiro, bem como a teoria do turismo em seu sentido amplo. Reflexões sobre a história de vida e o conhecimento das relações estabelecidas pelo escritor são essenciais para aprofundar os conhecimentos antropológicos pelos estudiosos da área turística.

Além de cumprir o objetivo, o conteúdo do artigo transcende a análise da proposta. Conhecer a biografia de Mário de Andrade e suas realizações, nos campos da cultura, da arte, da literatura, da pesquisa científica humana e social, da cultura e do próprio turismo, evoca a descoberta dos roteiros dos lugares em que ele viveu e dos legados deixados por onde ele circulou. Sugere-se, portanto, viajar pela obra de Mário de Andrade.

\section{REFERÊNCIAS}

Amaral, A. (1979). Artes plásticas na semana de 22. São Paulo: Perspectiva.

Andrade, M. de. (2002). Anteprojeto para a criação do serviço do Patrimônio Artístico Nacional. Revista do IPHAN, n.30, p.271-287.

Andrade, M. de. (1976). O Turista Aprendiz. São Paulo: Duas Cidades, Secretaria da Cultura, Ciência e Tecnologia. Andrade, M. de.(1927). Clan do Jaboti: Poesia. São Paulo, [s.n].

Andrade, M. de. Andrade, Mário de. (1964). Mário de Andrade a Sousa da Silveira. In: Revista do Livro. Rio de Janeiro, MinC/INL, n. 26, p.117-33.

Barretto, M. (2000). Turismo e legado cultural: As possibilidades do planejamento. Campinas: Papirus. 
Barretto, M. (2007). Cultura e turismo: discussões contemporâneas. Campinas: Papirus.

Barroso, Oswald. (2002). Usar, praticar e renovar. Jornal O Povo, Fortaleza, 17 fev.2002.

Bardin, L. (2011). Análise de conteúdo. Lisboa: Edições 70.

Beni, M. (2001). Análise estrutural do Turismo. São Paulo: Senac São Paulo

Buhalis, D. \& Leung, R. (2018). Smart hospitality - Interconnectivity and interoperability towards an ecosystem. International Journal of Hospitality Management, 71 (November 2017), 41-50. https://doi.org/10.1016/j.ijhm .2017.11.011.

Duarte, P. (1976). Mário de Andrade por ele mesmo. São Paulo: Hucitec.

Gastal, S., \& Castrogiovani, A. C. (Orgs). (1999). Turismo urbano: Cidades, sites de excitação turística. Porto Alegre: Edição dos Autores.

Geerzt, C. (1989). A interpretação das culturas. São Paulo: LTC.

Gonzaga, S. (1998). Manual de literatura brasileira. Porto Alegre: Mercado Aberto.

Heck, C. H. (2002). Apresentaçã.. Revista do IPHAN, n.30, p.1-2.

IPHAN - Instituto do Patrimônio Histórico e Artístico Nacional. (2002). O passado que explica o presente e prepara ofuturo. Brasília, s.n.

Katinsky, J. R. (2002). O Mestre-Aprendiz Mário e as artes plásticas. Revista do IPHAN, n.30, p.49-70.

Krippendorf, J. (2001). Sociologia do turismo: Para uma nova compreensão do lazer e das viagens. São Paulo: Aleph.

Lafetá, J. L. (1998). Mário de Andrade : seleção de textos, notas, estudos, biográficos, histórico e crítico. 2.ed. São Paulo: Nova Cultural.

Le Goff, Jacques. (1997). Patrimônio Histórico, cidadania e identidade cultural: o direito à memória. In: BITTENCOURT, C. (Org.) O saber histórico na sala de aula. São Paulo: Contexto, 1997, p.139.

Lopez, T. P. A. (1976). “Viagens Etnográficas” de Mário de Andrade. In: ANDRADE, Mário de. O Turista Aprendiz. São Paulo: Duas Cidades, Secretaria da Cultura, Ciência e Tecnologia, p.15\#23.

Lopez, T. P. A. Umprojeto de livro. (1976) In: Andrade, M. de. O Turista Aprendiz. São Paulo: Duas Cidades, Secretaria da Cultura, Ciência e Tecnologia, p.25\#33.

Lopez, T. P. A. A edição de “O Turista Aprendiz”. (1976). In: Andrade, M. de. O Turista Aprendiz. São Paulo: Duas Cidades, Secretaria da Cultura, Ciência e Tecnologia, p.35\#38.

Lopez, T. P. A. A bordo do diário. (1976). In: Andrade, M. de. O Turista Aprendiz. São Paulo: Duas Cidades, Secretaria da Cultura, Ciência e Tecnologia, p.39\#46.

Lopez, T. P. A. (Org). (1983). Mário de Andrade : entrevistas e depoimentos. São Paulo: T.A. Queiroz.

Lopez, T. P. A. (2002). Estabelecimento do texto, introdução e notas. In: Andrade, Mário de. O turista aprendiz. Belo Horizonte: Itatiaia.

Minayo, M.C.S. (Org.). (2001). Pesquisa social: teoria, método e criatividade. Rio de Janeiro: Vozes.

Moraes, R. (1994). Análise de conteúdo. Limites e possibilidades. In: Engers, M.E.A. (Org.). Paradigmas e metodologias em educação. Porto Alegre: Edipucrs.

Oriá, Ricardo. (2003). Memória e ensino de História. In Bittencourt, Circe (org.). O saber histórico na sala de aula. $8^{a}$ ed. São Paulo: Contexto, 2003.

Rezende, N. (2002). A Semana da Arte Moderna. São Paulo: Ática.

Richards, G. (2005). Introduction: culture and tourism in Europe. In Richards, G. (org). Cultural tourism in Europe. CABI, Wallingford: ATLAS. 8-20.

Rubino, S. (2002). A memória de Mário. Revista do IPHAN, n.30, p.139-154.

Sandroni, C. (2002). Mário, Oneyda, Dina e Claude. Revista do IPHAN, n.30, p.233-245.

. (1999). Notas sobre Mário de Andrade e a Missão de Pesquisas Folclóricas de 1938. Revista do IPHAN, n.28, p. 60-71.

Santos, J. L. dos. (1987). O que é Cultura. 6.ed. São Paulo: Brasiliense. 
Silva, F. F. da. (2002). Mário e o patrimônio: um anteprojeto ainda atual. Revista do IPHAN, n.30, p.129-137.

Swarbrooke, J., \& Horner, S. (2002). O comportamento do consumidor no turismo. São Paulo: Aleph.

Tomazzoni, E. L. (2009). Turismo e desenvolvimento regional: dimensões, elementos e indicadores. Caxias do Sul: Educs.

Toni, F. C. (2002). Me fiz brasileiro para o Brasil. Revista do IPHAN, n.30, p.73-85.

Torelly, L. P. P. (2015). O turista aprendiz e o patrimônio cultural. In. Lopez, T. A. e Figueiredo, T. L. (Ed.). O turista aprendiz/Mário de Andrade. IPHAN e Universidade de São Paulo. . (1993). Um dicionário musical. Cadernos Ponto \& Virgula, n.4, p.59-65.

Travassos, E. (2002). Mário e o folclore. Revista do IPHAN, n. 30, p.91-109.

(1997). Os mandarins milagrosos: arte e etnografia em Mário de Andrade e Béla Bartók / Elizabeth Travassos. - Rio de Janeiro: Funarte; Jorge Zahar Editor.

Tribe, J. (1997). The indiscipline of tourism. Annals of tourism research.v.24.

Trigo, L. G. G. (2001). Turismo básico. São Paulo: Senac.

Yázigi, E. (1998). Turismo: uma esperança condicional. São Paulo: Plêiade.

Wahab, S.\#E. (1991). A. Introdução à administração do turismo. São Paulo: Pioneira.

\section{Notas}

[1] Mário de Andrade nasceu na cidade de São Paulo, no dia 9 de outubro de 1893, na Rua Aurora no 320. Em 1909, tornouse bacharel em Ciências e Letras e entrou para a Congregação Mariana. Superando a perda dolorosa do irmão, em 1916, publicou Há uma gota de sangue em cada poema, sob o pseudônimo de Mário Sobral, e teve o seu primeiro contato com a modernidade na exposição da artista plástica Anita Malfati. Em 1922, publicou Paulicéia desvairada, poesia, seu primeiro livro, de feição moderna, que surgiu provocando muita polêmica. Em 1926, partiu de férias para a fazenda da família em Araraquara, escrevendo Macunaíma. Em 1927, iniciou sua experiência de fotógrafo aprendiz, que durou até 1929. Realizou sua primeira "viagem etnográfica”: ao Norte do Brasil (maio a agosto). Colaborou no Diário Nacional de São Paulo: crítico e e cronista do Arte (até 1932, quando o jornal é fechado). Publicou Amar, verbo intransitivo, romance, e Clã do Jaboti, poesia. Em 1928, tornou-se membro do Partido Democrático. (Lafetá, 1998; Lopez, 1976).

[2] Foi a Piracicaba e desenvolveu estudos sobre canto orfeônico. Colaborou na Revista de Antropofagia e em Verde. Ainda naquele ano, publicou Macunaíma, o herói sem nenhum caráter, rapsódia, e Ensaio sobre a música brasileira. Em 1929, iniciou sua coluna de crônicas, “Táxi”, no Diário Nacional. Escreveu poemas de "A costela de Grão\#cão”, publicou Samba rural paulista, estudo de folclore. Mário de Andrade morreu ao dia 25 de fevereiro de 1945, de infarto de miocárdio, em sua casa, na Rua Lopes Chaves, nº 546, em São Paulo, hoje, a Casa Mário de Andrade. Foi enterrado no Cemitério da Consolação. (Lafetá, 1998; Lopez, 1976).

[3] ANDRADE, Mário de. Mário de Andrade a Sousa da Silveira. In: Revista do Livro. Rio de Janeiro, MinC/INL, n.26, p.117-33, set.1964 